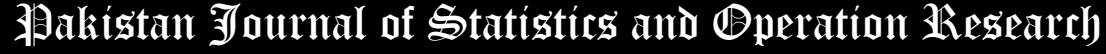

\section{Power Comparisons of Five Most Commonly Used Autocorrelation Tests}

\author{
Stanislaus S. Uyanto
}

School of Economics and Business, Atma Jaya Catholic University of Indonesia, stan.uyanto@atmajaya.ac.id

\begin{abstract}
In regression analysis, autocorrelation of the error terms violates the ordinary least squares assumption that the error terms are uncorrelated. The consequence is that the estimates of coefficients and their standard errors will be wrong if the autocorrelation is ignored. There are many tests for autocorrelation, we want to know which test is more powerful. We use Monte Carlo methods to compare the power of five most commonly used tests for autocorrelation, namely Durbin-Watson, Breusch-Godfrey, Box-Pierce, Ljung Box, and Runs tests in two different linear regression models. The results indicate the Durbin-Watson test performs better in the regression model without lagged dependent variable, although the advantage over the other tests reduce with increasing autocorrelation and sample sizes. For the model with lagged dependent variable, the Breusch-Godfrey test is generally superior to the other tests.
\end{abstract}

Key Words: Correlated error terms; Ordinary least squares assumption; Residuals; Regression diagnostic; Lagged dependent variable.

Mathematical Subject Classification: 62J05; 62J20.

\section{Introduction}

An important assumption of the classical linear regression model states that there is no autocorrelation in the error terms. Autocorrelation of the error terms violates the ordinary least squares assumption that the error terms are uncorrelated, meaning that the Gauss Markov theorem (Plackett, 1949, 1950; Greene, 2018) does not apply, and that ordinary least squares estimators are no longer the best linear unbiased estimators.

A search on autocorrelation tests available in statistical software such as EViews, IBM SPSS, MATLAB, Minitab, R, SAS, SHAZAM, S-Plus, and Stata revealed that the commonly available autocorrelation tests in these software are Durbin-Watson, Breusch-Godfrey, Box-Pierce, Ljung Box, and Runs tests. Table 1 lists the autocorrelation tests available for these statistical software packages.

Comparison of the autocorrelation tests has received attention in the literature. L'Esperance and Taylor (1975), by Monte Carlo simulation, presents comparisons of four autocorrelation tests (Durbin-Watson bounds test, a test based on Theil's best linear unbiased scalar estimator, a test devised by Abrahamse, Koerts and Louter, and an exact test devised by Durbin). Smith (1976) compared different autocorrelation tests (the Durbin-Watson test, Durbin cumulated periodogram test, Durbin test, Geary sign test and Schmidt tests). 
Table 1: Autocorrelation tests available in statistical software packages

\begin{tabular}{lccccc}
\hline \multirow{2}{*}{$\begin{array}{c}\text { Statistical } \\
\text { software }\end{array}$} & \multicolumn{5}{c}{ Tests for autocorrelation } \\
\cline { 2 - 6 } & $\begin{array}{c}\text { Durbin- } \\
\text { Watson }\end{array}$ & $\begin{array}{c}\text { Breusch- } \\
\text { Godfrey }\end{array}$ & $\begin{array}{c}\text { Box- } \\
\text { Pierce }\end{array}$ & $\begin{array}{c}\text { Ljung- } \\
\text { Box }\end{array}$ & $\begin{array}{c}\text { Runs } \\
\text { test }\end{array}$ \\
\hline EViews & $\sqrt{ }$ & $\sqrt{ }$ & - & $\sqrt{ }$ & $\sqrt{ }$ \\
IBM SPSS & $\sqrt{ }$ & - & - & - & $\sqrt{ }$ \\
MATLAB & $\sqrt{ }$ & $\sqrt{ }$ & - & $\sqrt{ }$ & $\sqrt{ }$ \\
Minitab & $\sqrt{ }$ & - & - & $\sqrt{ }$ & $\sqrt{ }$ \\
R & $\sqrt{ }$ & $\sqrt{ }$ & $\sqrt{ }$ & $\sqrt{ }$ & $\sqrt{ }$ \\
SAS & $\sqrt{ }$ & $\sqrt{ }$ & - & $\sqrt{ }$ & $\sqrt{ }$ \\
SHAZAM & $\sqrt{ }$ & $\sqrt{ }$ & - & $\sqrt{ }$ & $\sqrt{ }$ \\
SPlus & $\sqrt{ }$ & $\sqrt{ }$ & $\sqrt{ }$ & $\sqrt{ }$ & $\sqrt{ }$ \\
Stata & $\sqrt{ }$ & $\sqrt{ }$ & $\sqrt{ }$ & $\sqrt{ }$ & $\sqrt{ }$ \\
\hline
\end{tabular}

In this paper, we use Monte Carlo methods to compare the power of the five most commonly used statistical tests for autocorrelation, namely the Durbin-Watson (Durbin and Watson, 1950, 1951, 1971; Greene, 2018), Breusch-Godfrey (Breusch, 1978; Godfrey, 1978; Asteriou and Hall, 2017), Box- Pierce (Box and Pierce, 1970; Greene, 2018), LjungBox (Ljung and Box, 1978; Verbeek, 2017), and Runs test (Wald and Wolfowitz, 1943; Gujarati and Porter, 2009), in two different linear regression models: without lagged dependent variable and with lagged dependent variable.

\section{Tests for Autocorrelation}

We give a short description of the five methods of testing for Autocorrelation.

\section{Durbin-Watson test}

The most frequently used statistical test for detecting autocorrelation is the Durbin-Watson test (Durbin and Watson, 1950, 1951, 1971; Greene, 2018) which is defined based on the ordinary least squares residuals.

If $u_{t}$ is the residual associated with the observation at time $t$, then the Durbin-Watson $d$-statistic is

where $n$ is the number of observations.

$$
d=\frac{\sum_{t=2}^{n}\left(\widehat{u}_{t}-\widehat{u}_{t-1}\right)^{2}}{\sum_{t=1}^{n} \widehat{u}^{2} t}
$$

The value of Durbin Watson $d$-statistic in Equation (1) always lies between 0 and 4. Harvey (1990) notes that, for large sample sizes, the Durbin-Watson test statistic $d$ is approximately normally distributed with mean $=2$ and variance $=4 / n$. Durbin-Watson $d$-statistic is not applicable when lagged dependent variables are included in the explanatory variables.

\section{Breusch-Godfrey test}

Breusch (1978) and Godfrey (1978) (see also Asteriou and Hall, 2017) have developed a test of autocorrelation that is more flexible, covering autocorrelation of higher orders and applicable whether or not the regressors include lags of the dependent variable. Using simple regression model,

$$
Y_{t}=\beta_{1}+\beta_{2} X_{t}+u_{t}
$$

The simple regression model Equation (2) is first fitted by ordinary least squares to obtain a set of sample residuals $\hat{u}_{t}$.

Breusch and Godfrey proved that, if the following auxiliary regression model is fitted

$$
\hat{u}_{t}=\alpha_{1}+\alpha_{2} X_{t}+\hat{\rho}_{1} \hat{u}_{t-1}+\hat{\rho}_{2} \hat{u}_{t-2}+\cdots+\hat{\rho}_{p} \hat{u}_{t-p}+\varepsilon_{t}
$$

and obtain $R^{2}$ from this auxiliary regression Equation (3), then, asymptotically, it can be shown that

$$
(n-p) R^{2} \sim \chi_{p}^{2}
$$




\section{Box-Pierce test}

Box and Pierce (1970) (see also Greene, 2018) introduced the portmanteau statistic

$$
Q=n \sum_{k=1}^{h} r_{k}^{2}
$$

where $n$ is the sample size, $r_{k}$ is the sample autocorrelation at lag $k$, and $h$ is the number of lags being tested. Under $H_{0}$ of no autocorrelations the statistic $Q$ in Equation (4) follows a $\chi_{(h)}^{2}$. Box-Pierce test $Q$ is not valid when lagged dependent variables exist in the regressor.

\section{Ljung-Box test}

Another test for assessing autocorrelation is the Ljung and Box (1978) (see also Verbeek, 2017). Ljung and Box (1978) modified Box and Pierce (1970) test statistic by

$$
Q=n(n+2) \sum_{k=1}^{h} \frac{r_{k}^{2}}{n-k}
$$

where $n$ is the sample size, $r_{k}$ is the sample autocorrelation at lag $k$, and $h$ is the number of lags being tested. Under $H_{0}$ of no autocorrelations the statistic $Q$ follows a $\chi_{(h)}^{2}$. Hyndman and Athanasopoulos (2013) suggest using $h=$ $\min (10, n / 5)$ for Equation (5). Ljung-Box test $Q$ is not valid when lagged dependent variables exist in the regressor.

\section{Runs test}

Runs test of randomness (Wald and Wolfowitz, 1943; see also Gujarati and Porter, 2009) is a statistical test that is used to know the randomness in data. Runs test of randomness is an alternative test to test autocorrelation in the residuals (Geary, 1970). If there is no autocorrelation, then the residuals are distributed randomly. A run is defined as a series of consecutive positive (or negative) values. Let $n=$ total number of observations, $n_{1}=$ number of positive residuals, $n_{2}=$ number of negative residuals, $n=n_{1}+n_{2}$, and $R=$ number of runs. Asuming that $n_{1}>10$ and $n_{2}$ $>10$, then under the null hypothesis that the successive residuals are random, the number of runs is asymptotically normally distributed.

The test statistic is

with mean

$$
Z=\frac{R-E(R)}{s_{R}}
$$

and variance

$$
E(R)=\frac{2 n_{1} n_{2}}{n}+1
$$

$$
S_{R}^{2}=\frac{2 n_{1} n_{2}\left(2 n_{1} n_{2}-n\right)}{n^{2}(n+1)}
$$

\section{Monte Carlo method}

Power comparisons of tests for autocorrelation are made by using Monte Carlo method for simulation. We use $R$ for Windows $(R$ Core Team, 2019) for doing the simulation. We carried out simulations for six different sample sizes $n=15,30,60,100,150,200$. The number of simulation is 10000 and the level of significance $\alpha=0.05$.

The model equations used in the simulation are model without lagged dependent variable with regressor $x_{i}=i$ :

$$
y_{i}=\beta_{1}+\beta_{2} i+u_{i}
$$

and model with lagged dependent variable with regressor $x_{i}=y_{i-1}$ :

$$
y_{i}=\beta_{1}+\beta_{2} y_{i-1}+u_{i}
$$

with the regression coefficients in both models $\beta_{1}=0.4, \beta_{2}=-0.7$, and $u_{i}$ is a stationary autoregressive $\operatorname{AR}(1)$ series, derived from standard normal innovations for autocorrelation $\rho=0,0.2,0.4,0.6,0.8,0.9,0.99$. 
We compute the power of the test as the proportion of times we correctly reject the null hypothesis.

The following are the simulation steps:

1. Generate the sample data for the model without lagged dependent variable and the model with a lagged dependent variable.

2. Perform the five autocorrelation tests and calculate their $\mathrm{p}$-values.

3. Repeat steps $1-2,10000$ times.

4. Calculate the power of the test as the proportion of times we correctly reject the null hypothesis.

5. Repeat steps $1-4$ for $\rho=0,0.2,0.4,0.6,0.8,0.9,0.99$

6. Repeat steps $1-5$ for $n=15,30,60,100,150,200$.

\section{Results and Conclusion}

Tables 2 and 3 respectively report the powers of the five autocorrelation tests for model without lagged dependent variabel and model with lagged dependent variable.

The difference of the power of the tests becomes more apparent when the comparison is carried out graphically. Figures 1 and 2 respectively present the simulated power curves for Durbin-Watson, Breusch-Godfrey, Box-Pierce, Ljung-Box, and Runs tests for autocorrelation with $\rho=0,0.2,0.4,0.6,0.8,0.9,0.99$ and six different sample sizes $n$ $=15,30,60,100,150,200$. based on the results of Tables 2 and 3 . The vertical axis of the figures measures the power of the five tests, and the horizontal axis represents the value of the autocorrelation $\rho$.

Examining the results in Figure 1 and Table 2 reveal that the Durbin-Watson test performs better in the model without lagged dependent variable, although the advantage over the Breusch-Godfrey, Box-Pierce, Ljung Box, and Runs tests reduce with increasing autocorrelation $\rho$ and sample size $n$.

For the model with lagged dependent variable, Figure 2 and Table 3 reveal that the Breusch-Godfrey test is generally superior to the other tests. The Durbin-Watson test, Box-Pierce, Ljung Box, and Runs tests have very low power except for very high correlations. Note that the Durbin-Watson, Box-Pierce, Ljung Box tests are not valid when lagged dependent variables exist in the regressor.

In conclusion, the Durbin-Watson test performs better in the regression model without lagged dependent variable, although the advantage over the other tests reduce with increasing autocorrelation and sample sizes. For the model with lagged dependent variable, the Breusch-Godfrey test is generally superior to the other tests. 
Table 2: The powers of Durbin-Watson, Breusch-Godfrey, Box-Pierce, Ljung-Box, and Runs-test tests for autocorrelation with $\rho=0,0.2,0.4,0.6,0.8,0.9,0.99$ and sample sizes $n=15,30,60,100,150,200$ (without lagged dependent variable)

\begin{tabular}{|c|c|c|c|c|c|c|c|c|}
\hline & & \multicolumn{7}{|c|}{ Autocorrelation } \\
\hline & Samples $(n)$ & 0 & 0.2 & 0.4 & 0.6 & 0.8 & 0.9 & 0.99 \\
\hline \multirow[t]{6}{*}{ Durbin-Watson test } & 15 & 0.054 & 0.095 & 0.224 & 0.398 & 0.564 & 0.628 & 0.655 \\
\hline & 30 & 0.050 & 0.163 & 0.485 & 0.812 & 0.951 & 0.972 & 0.983 \\
\hline & 60 & 0.052 & 0.313 & 0.834 & 0.989 & 1.000 & 1.000 & 1.000 \\
\hline & 100 & 0.049 & 0.495 & 0.968 & 1.000 & 1.000 & 1.000 & 1.000 \\
\hline & 150 & 0.049 & 0.659 & 0.997 & 1.000 & 1.000 & 1.000 & 1.000 \\
\hline & 200 & 0.049 & 0.788 & 1.000 & 1.000 & 1.000 & 1.000 & 1.000 \\
\hline \multirow[t]{6}{*}{ Breusch-Godfrey test } & 15 & 0.062 & 0.032 & 0.062 & 0.151 & 0.287 & 0.339 & 0.364 \\
\hline & 30 & 0.052 & 0.078 & 0.322 & 0.685 & 0.895 & 0.939 & 0.958 \\
\hline & 60 & 0.055 & 0.212 & 0.752 & 0.980 & 1.000 & 1.000 & 1.000 \\
\hline & 100 & 0.050 & 0.406 & 0.950 & 1.000 & 1.000 & 1.000 & 1.000 \\
\hline & 150 & 0.049 & 0.596 & 0.996 & 1.000 & 1.000 & 1.000 & 1.000 \\
\hline & 200 & 0.051 & 0.745 & 1.000 & 1.000 & 1.000 & 1.000 & 1.000 \\
\hline \multirow[t]{6}{*}{ Box-Pierce test } & 15 & 0.050 & 0.023 & 0.048 & 0.117 & 0.238 & 0.281 & 0.302 \\
\hline & 30 & 0.048 & 0.072 & 0.307 & 0.668 & 0.885 & 0.931 & 0.953 \\
\hline & 60 & 0.052 & 0.206 & 0.748 & 0.979 & 1.000 & 1.000 & 1.000 \\
\hline & 100 & 0.049 & 0.402 & 0.950 & 1.000 & 1.000 & 1.000 & 1.000 \\
\hline & 150 & 0.048 & 0.595 & 0.996 & 1.000 & 1.000 & 1.000 & 1.000 \\
\hline & 200 & 0.051 & 0.744 & 1.000 & 1.000 & 1.000 & 1.000 & 1.000 \\
\hline \multirow[t]{6}{*}{ Ljung-Box test } & 15 & 0.083 & 0.043 & 0.081 & 0.177 & 0.316 & 0.363 & 0.386 \\
\hline & 30 & 0.063 & 0.088 & 0.344 & 0.700 & 0.901 & 0.941 & 0.960 \\
\hline & 60 & 0.059 & 0.223 & 0.762 & 0.980 & 1.000 & 1.000 & 1.000 \\
\hline & 100 & 0.052 & 0.414 & 0.953 & 1.000 & 1.000 & 1.000 & 1.000 \\
\hline & 150 & 0.051 & 0.602 & 0.996 & 1.000 & 1.000 & 1.000 & 1.000 \\
\hline & 200 & 0.053 & 0.748 & 1.000 & 1.000 & 1.000 & 1.000 & 1.000 \\
\hline \multirow[t]{6}{*}{ Runs test } & 15 & 0.022 & 0.031 & 0.066 & 0.127 & 0.213 & 0.249 & 0.265 \\
\hline & 30 & 0.036 & 0.063 & 0.179 & 0.392 & 0.635 & 0.732 & 0.775 \\
\hline & 60 & 0.053 & 0.135 & 0.447 & 0.799 & 0.968 & 0.989 & 0.996 \\
\hline & 100 & 0.052 & 0.234 & 0.703 & 0.968 & 1.000 & 1.000 & 1.000 \\
\hline & 150 & 0.060 & 0.330 & 0.881 & 0.997 & 1.000 & 1.000 & 1.000 \\
\hline & 200 & 0.053 & 0.420 & 0.953 & 1.000 & 1.000 & 1.000 & 1.000 \\
\hline
\end{tabular}


Table 3: The powers of Durbin-Watson, Breusch-Godfrey, Box-Pierce, Ljung-Box, and Runs tests for autocorrelation with $\rho=0,0.2,0.4,0.6,0.8,0.9,0.99$ and sample sizes $n=15,30,60,100,150,200$ (with lagged dependent variable).

\begin{tabular}{|c|c|c|c|c|c|c|c|c|}
\hline & & \multicolumn{7}{|c|}{ Autocorrelation } \\
\hline & Samples $(n)$ & 0 & 0.2 & 0.4 & 0.6 & 0.8 & 0.9 & 0.99 \\
\hline \multirow[t]{6}{*}{ Durbin-Watson test } & 15 & 0.012 & 0.004 & 0.004 & 0.004 & 0.003 & 0.003 & 0.011 \\
\hline & 30 & 0.008 & 0.004 & 0.005 & 0.005 & 0.007 & 0.022 & 0.177 \\
\hline & 60 & 0.007 & 0.009 & 0.019 & 0.014 & 0.030 & 0.269 & 0.719 \\
\hline & 100 & 0.006 & 0.019 & 0.051 & 0.027 & 0.101 & 0.630 & 0.960 \\
\hline & 150 & 0.006 & 0.033 & 0.122 & 0.049 & 0.195 & 0.858 & 0.997 \\
\hline & 200 & 0.005 & 0.063 & 0.225 & 0.077 & 0.292 & 0.950 & 1.000 \\
\hline \multirow[t]{6}{*}{ Breusch-Godfrey test } & 15 & 0.061 & 0.040 & 0.045 & 0.078 & 0.115 & 0.154 & 0.247 \\
\hline & 30 & 0.054 & 0.055 & 0.146 & 0.307 & 0.485 & 0.586 & 0.719 \\
\hline & 60 & 0.054 & 0.113 & 0.414 & 0.733 & 0.878 & 0.944 & 0.978 \\
\hline & 100 & 0.050 & 0.204 & 0.693 & 0.928 & 0.967 & 0.993 & 0.999 \\
\hline & 150 & 0.050 & 0.311 & 0.892 & 0.977 & 0.986 & 0.999 & 1.000 \\
\hline & 200 & 0.051 & 0.424 & 0.967 & 0.990 & 0.991 & 1.000 & 1.000 \\
\hline \multirow[t]{6}{*}{ Box-Pierce test } & 15 & 0.004 & 0.001 & 0.000 & 0.000 & 0.000 & 0.001 & 0.018 \\
\hline & 30 & 0.005 & 0.001 & 0.001 & 0.002 & 0.005 & 0.034 & 0.230 \\
\hline & 60 & 0.005 & 0.005 & 0.012 & 0.007 & 0.038 & 0.312 & 0.756 \\
\hline & 100 & 0.006 & 0.014 & 0.038 & 0.020 & 0.120 & 0.660 & 0.966 \\
\hline & 150 & 0.005 & 0.027 & 0.104 & 0.040 & 0.218 & 0.872 & 0.998 \\
\hline & 200 & 0.005 & 0.053 & 0.200 & 0.064 & 0.314 & 0.956 & 1.000 \\
\hline \multirow[t]{6}{*}{ Ljung-Box test } & 15 & 0.010 & 0.003 & 0.001 & 0.001 & 0.001 & 0.003 & 0.033 \\
\hline & 30 & 0.007 & 0.003 & 0.002 & 0.003 & 0.007 & 0.044 & 0.256 \\
\hline & 60 & 0.006 & 0.007 & 0.013 & 0.009 & 0.043 & 0.328 & 0.767 \\
\hline & 100 & 0.006 & 0.015 & 0.043 & 0.022 & 0.127 & 0.673 & 0.967 \\
\hline & 150 & 0.005 & 0.029 & 0.110 & 0.042 & 0.224 & 0.876 & 0.998 \\
\hline & 200 & 0.005 & 0.055 & 0.206 & 0.067 & 0.319 & 0.957 & 1.000 \\
\hline \multirow[t]{6}{*}{ Runs test } & 15 & 0.017 & 0.025 & 0.035 & 0.036 & 0.037 & 0.032 & 0.031 \\
\hline & 30 & 0.016 & 0.024 & 0.033 & 0.037 & 0.041 & 0.055 & 0.128 \\
\hline & 60 & 0.029 & 0.039 & 0.057 & 0.057 & 0.068 & 0.171 & 0.457 \\
\hline & 100 & 0.030 & 0.057 & 0.093 & 0.080 & 0.113 & 0.380 & 0.803 \\
\hline & 150 & 0.030 & 0.074 & 0.138 & 0.097 & 0.159 & 0.578 & 0.952 \\
\hline & 200 & 0.029 & 0.086 & 0.162 & 0.108 & 0.194 & 0.707 & 0.992 \\
\hline
\end{tabular}



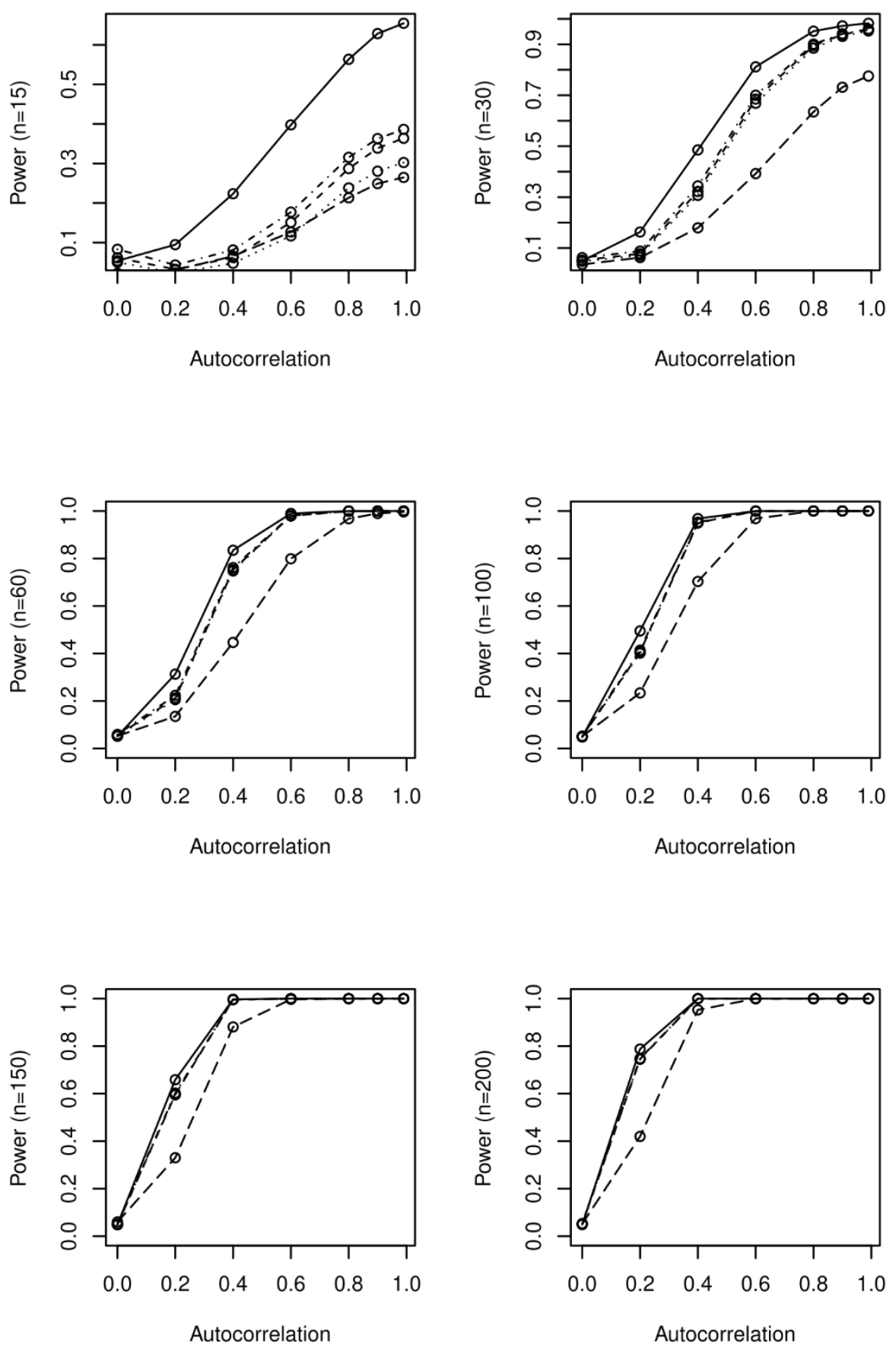

Figure 1: Simulated power curves for Durbin-Watson (solid), Breusch-Godfrey (dashed), Box-Pierce (dotted), Ljung-Box (dotdash), and Runs (longdash) tests for autocorrelation with $\rho=0,0.2,0.4,0.6,0.8,0.9,0.99$ and sample sizes $n=15,30$, 60, 100, 150, 200 (without lagged dependent variable). 

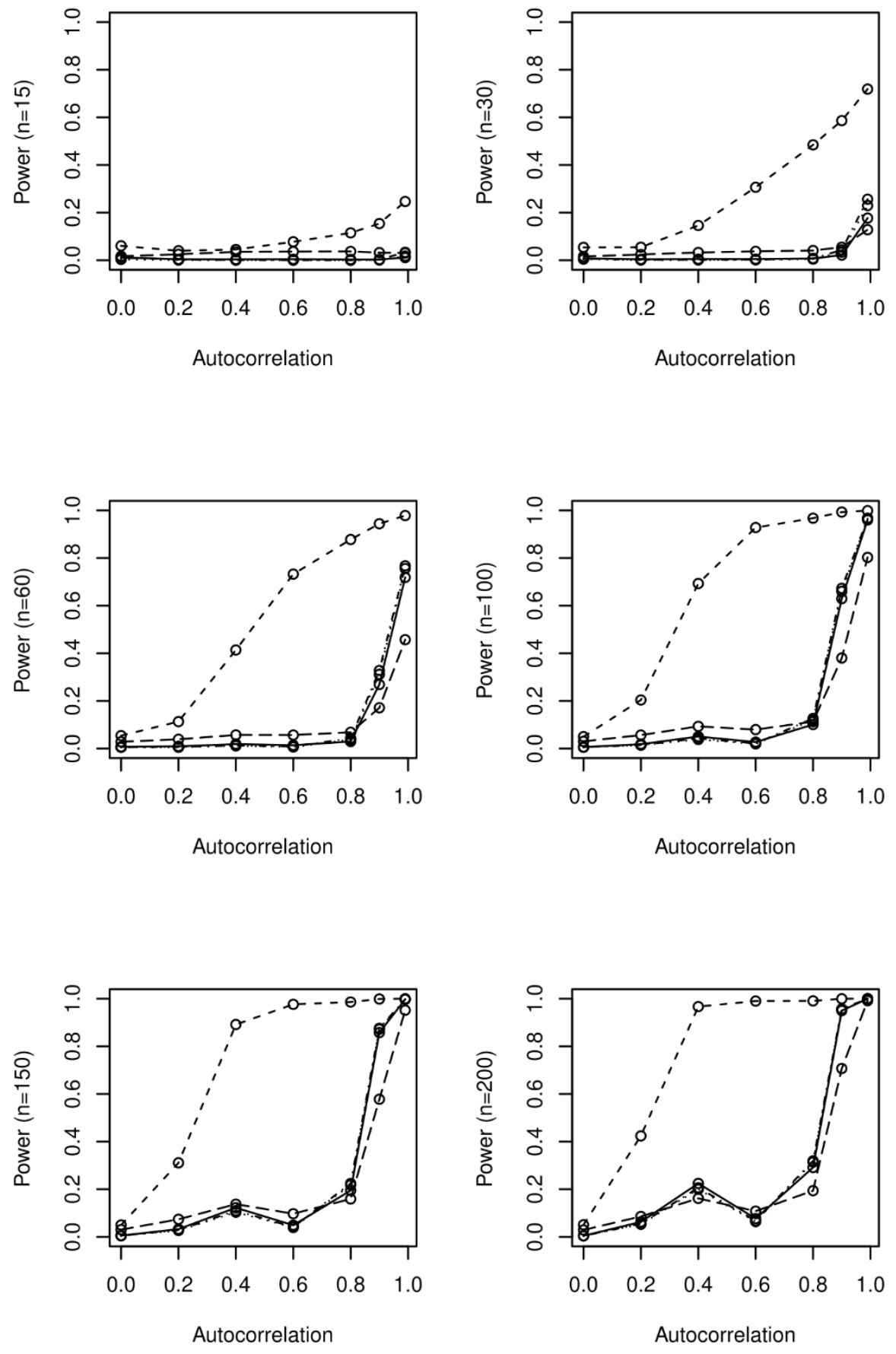

Figure 2: Simulated power curves for Durbin-Watson (solid), Breusch-Godfrey (dashed), Box-Pierce (dotted), LjungBox (dotdash), and Runs (longdash) tests for autocorrelation with $\rho=0,0.2,0.4,0.6,0.8,0.9,0.99$ and six different sample sizes $n=15,30,60,100,150,200$ (with lagged dependent variable). 


\section{Acknowledgements}

The author would like to thank the reviewers for their valuable comments and suggestions which led to improvements of this paper.

\section{References}

1. Asteriou, D. and Hall, S. G. (2017). Applied Econometrics. Palgrave Macmillan, New York, N.Y., 3rd edition.

2. Box, G. E. P. and Pierce, D. A. (1970). Distribution of residual autocorrelations in autoregressive-integrated moving average time series models. Journal of the American Statistical Association, 65(332):1509 - 1526.

3. Breusch, T. S. (1978). Testing for autocorrelation in dynamic linear models. Australian Economic Papers., 17:334 - 355.

4. Durbin, J. and Watson, G. S. (1950). Testing for serial correlation in least squares regression i. Biometrika, 37(3/4):409 - 2428.

5. Durbin, J. and Watson, G. S. (1951). Testing for serial correlation in least squares regression ii. Biometrika, 38(1/2):159- 177 .

6. Durbin, J. and Watson, G. S. (1971). Testing for serial correlation in least squares regression iii. Biometrika, 58(1): $1-19$.

7. Geary, R. (1970). Relative efficiency of count of sign changes for assessing residual autoregression in least squares regression. Biometrika, 57(1):123 - 127.

8. Godfrey, L. G. (1978). Testing against general autoregressive and moving average error models when the regres- sors include lagged dependent variables. Econometrica, 46(6):1293 - 1302.

9. Greene, W. H. (2018). Econometric Analysis. Pearson Education, Inc., New York, N.Y., 8th edition.

10. Gujarati, D. N. and Porter, D. C. (2009). Basic Econometrics. McGraw-Hill/Irwin, New York, NY, 5th edition. Harvey, A. C. (1990). The Econometric Analysis of Time Series. MIT Press, London, UK, second edition.

11. Hyndman, R. J. and Athanasopoulos, G. (2013). Forecasting: principles and practice. OTexts, Melbourne, Australia.

12. L'Esperance, W. L. and Taylor, D. (1975). The power of four tests of autocorrelation in the linear regression model. Journal of Econometrics, 3(1):1 - 21.

13. Ljung, G. M. and Box, G. E. P. (1978). On a measure of lack of fit in time series models. Biometrika, 65(2):297-303.

14. Plackett, R. L. (1949). A historical note on the method of least squares. Biometrika, 36(3/4):458 - 460. Plackett, R. L. (1950). Some theorems in least squares. Biometrika, 37(1/2):149 - 157.

15. R Core Team (2019). R: A Language and Environment for Statistical Computing. R Foundation for Statistical Computing, Vienna, Austria. URL https://www.R-project.org/.

16. Smith, V. K. (1976). The estimated power of several tests for autocorrelation with non-first- order alternatives.

17. Journal of the American Statistical Association, 71(356):879 - 883.

18. Verbeek, M. (2017). A Guide to Modern Econometrics. John Wiley \& Sons, Inc., Hoboken, NJ, 5th edition.

19. Wald, A. and Wolfowitz, J. (1943). An exact test for randomness in the non-parametric case based on serial

20. correlation. The Annals of Mathematical Statistics, 14(4):378 - 388. 


\section{Appendix 1. R code for Comparison of Five Autocorrelation Tests}

The $\mathrm{R}$ code for comparison of the five autocorrelation tests is as follows

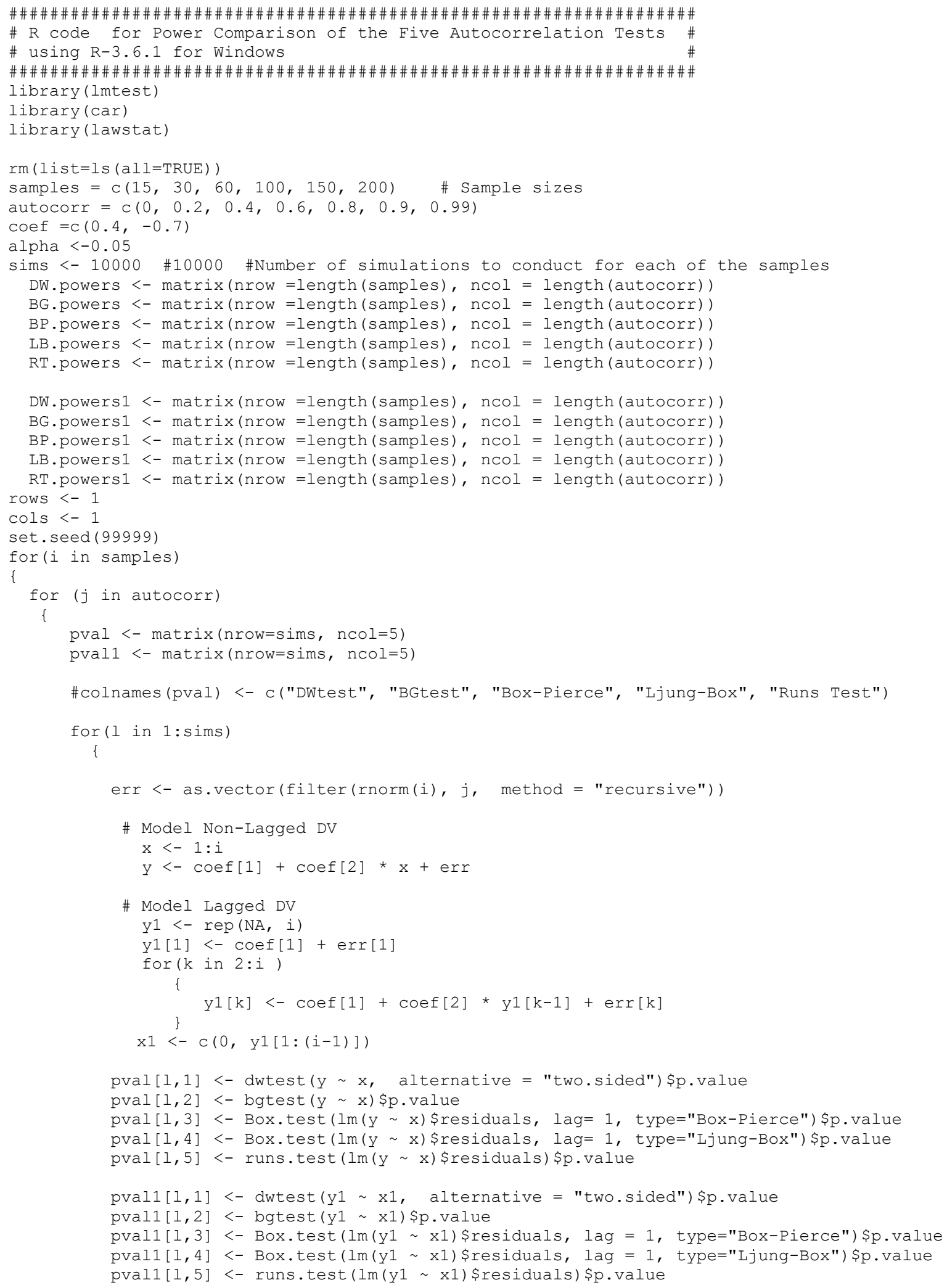




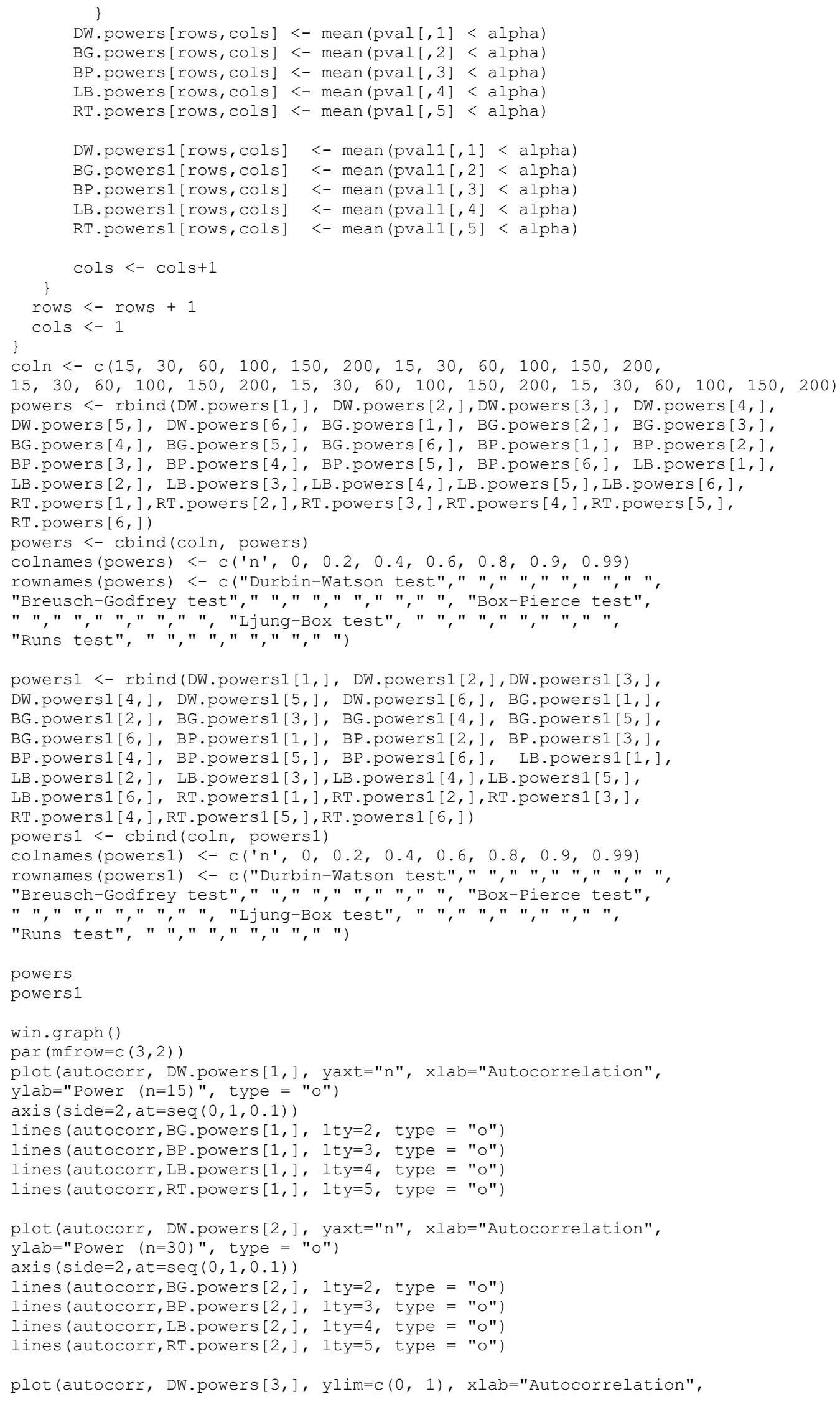




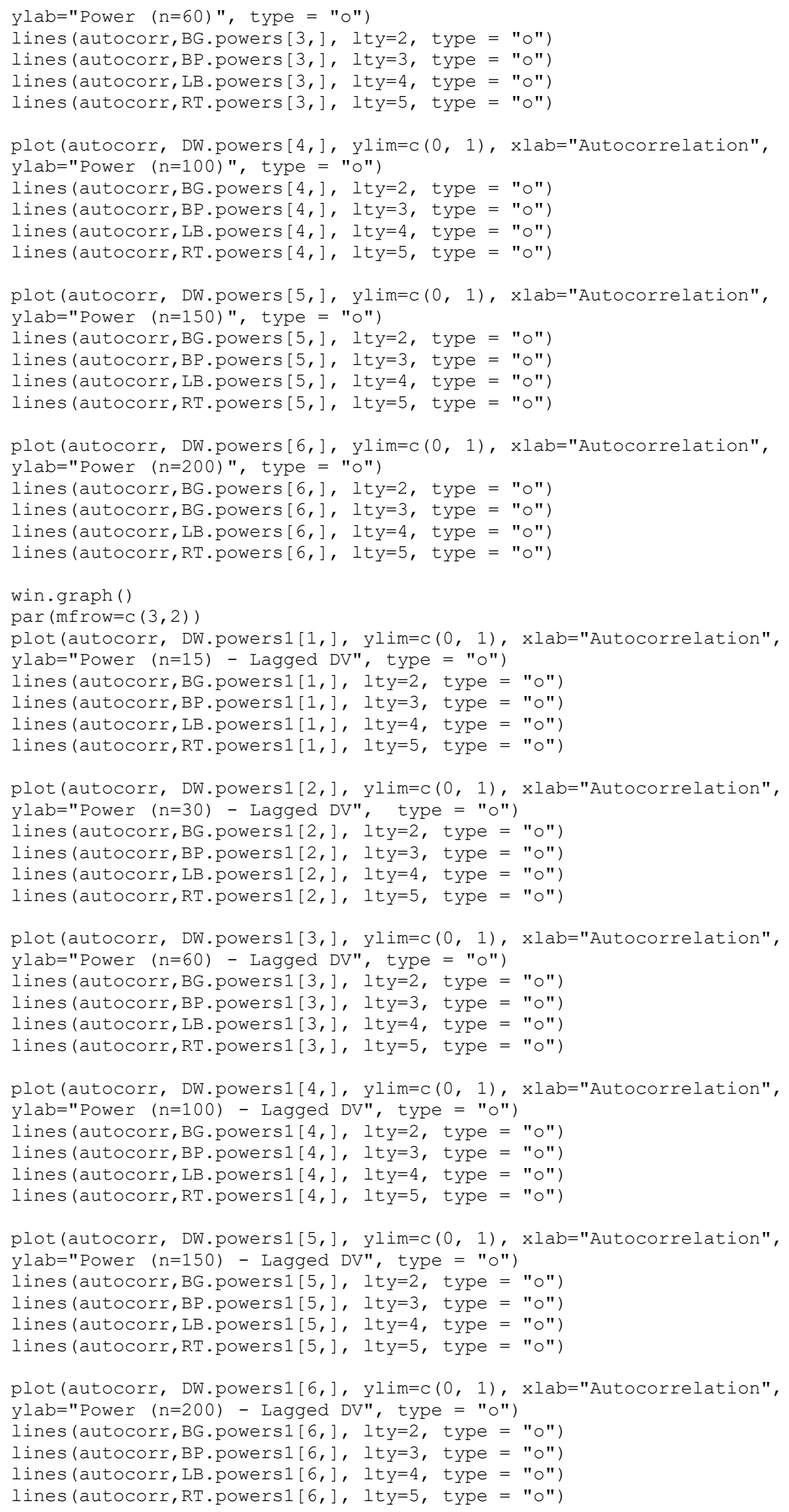

